\title{
The relationship between non-cognitive student attributes and academic achievements in a flipped learning classroom of a pre-dental science course
}

\author{
Minsun $\mathrm{Kim}^{1}$, Sangho $\mathrm{Roh}^{2, *}$ and Jungjoon $\mathrm{Ihm}^{3, *}$ \\ ${ }^{1}$ Center for Education Quality Management, Konkuk University and ${ }^{2}$ Department of Oral Biochemistry and ${ }^{3}$ Dental \\ Research Institute, Seoul National University School of Dentistry, Seoul, Korea
}

Purpose: The purpose of this study was to examine whether non-cognitive student attributes such as learning style and personality type affected academic performance in a flipped learning classroom of a pre-dental undergraduate science course.

Methods: 'Biodiversity and Global Environment,' a 15-week, 3-credit course, was designed as a flipped class in Seoul National University School of Dentistry in 2017. Second-year pre-dental students were required to enroll in the course and to engage in online learning and in-class discussion. The Kolb's Learning Style Inventory and the Myers-Briggs Type Indicator were conducted to measure non-cognitive student factors. Independent samples t-test and multivariate regression analyses were used to examine the relationships between self-rated measurements and academic achievement.

Results: More than half of the students enrolled in the flipped science course had an assimilator learning style (50\%), followed by convergers $(24 \%)$, accommodators $(16 \%)$, and divergers $(10 \%)$, and their personality types were dominated by the introverted, sensing, thinking, and judging types, respectively. Examining group differences using the t-test demonstrated a significant relationship between the diverger group and higher academic success. In particular, the multivariate regression analysis indicated that both thinking types and female students performed better in discussion than feeling types and male students.

Conclusion: To operate the flipped learning classroom more effectively in medical and dental education, the instructor should carefully develop and apply a more tailored facilitation and relevant assessment by considering student learning styles and personality types.

Key Words: Student attributes, Myers-Briggs Type Indicator, Flipped learning, Dental education

\section{Introduction}

Since its inception in 2007, the flipped classroom has reversed the traditional learning environment from being instructor-centered to student-centered [1]. Dental educators found the traditional lecture model to have several limitations, such as one-way communication, lack of interaction, and poor student engagement [1,2]. In light of these disadvantages of the lecture classroom, the flipped classroom model has been introduced in most dental schools in Korea.

However, whether the flipped classroom can be sufficiently effective to challenge the traditional peda-
Received: September 1, 2018 • Revised: October 19, 2018 • Accepted: November 7, 2018 Corresponding Author: Jungjoon Ihm (https://orcid.org/0000-0002-3136-5956)

School of Dentistry, Seoul National University, 1 Gwanak-ro, Gwanak-gu, Seoul 08826, Korea Tel: +82.2.880.2343 Fax: +82.2.882.0228 email: ijj127@snu.ac.kr Corresponding Author: Sangho Roh (https://orcid.org/0000-0001-8082-6459)

School of Dentistry, Seoul National University, 1 Gwanak-ro, Gwanak-gu, Seoul 08826, Korea Tel: +82.2.880.2333 Fax: +82.2.883.2383 email: sangho@snu.ac.kr

*These two authors contributed equally to this work.
Korean J Med Educ 2018 Dec; 30(4): 339-346.

https://doi.org/10.3946/kjme.2018.109

eISSN: 2005-7288

(C) The Korean Society of Medical Education. All rights reserved. This is an open-access article distributed under the terms of the Creative Commons Attribution Non-Commercial License (http:// creativecommons.org/licenses/by-nc/3.0/), which permits unrestricted non-commercial use, distribution, and reproduction in any medium, provided the original work is properly cited. 
gogy in dental education is debatable. Even though more medical and dental schools have begun to implement flipped classrooms as an innovative pedagogy, studies found the success of a flipped classroom to be dependent on individual student attributes that influence their learning experiences and learning outcomes [2,3]. It was reported that, for those students preferring traditional lectures, the flipped course instruction would not significantly affect their perceptions of the learning experience [2].

When considering student attributes in the learning experience, the level of intellectual achievement was significantly influenced by non-cognitive and cognitive factors. Recently, an increasing number of studies have focused on how non-cognitive factors shaped student academic performance [4-6]. Previous studies found that, among non-cognitive student factors, student learning style and academic strategy preference can be combined with appropriate lecturing methods to result in desirable learning achievements [7]. In particular, personality type, which is expressed as an individual's unique behavior and thinking style, is considered to be a significant non-cognitive factor that affects not only student academic achievement, but also career and major selection [8].

As non-cognitive elements, learning style and personality type were reported to be closely related to academic performance [9,10]. Based on this finding, there have been attempts to analyze academic achievement in different major fields, such as engineering and nursing [11-13]. In this study, Kolb's empirical learning model, the most common learning style of adults, and the Myers-Briggs Type Indicator (MBTI), which is the representative tool invented based on a psychological typology of Jung et al. [11] to measure an individual's personality, were used to investigate the effects of learning style and personality type on academic achieve- ment [14].

The purpose of this study was to examine whether students' non-cognitive attributes, such as learning style and personality type, affected academic performance in a flipped learning classroom of a pre-dental undergraduate science course. The focus of the study was based on the assumption that the general benefits of a flipped classroom depend on the non-cognitive attributes of dental students, some of which can be measured using the Kolb's Learning Style Inventory and MBTI.

\section{Methods}

'Biodiversity and Global Environment,' a 15-week, 3credit course, was designed as a flipped learning class in 2017. Second-year pre-dental students in Seoul National University School of Dentistry were required to enroll in the course and to participate in online learning and in-class discussion. The Kolb's Learning Style Inventory and the MBTI were conducted to measure student learning and personality types at the beginning of the course. A total of fifty pre-dental students consented to the collection of records and completed the surveys.

In this study, the flipped-course combined distance learning and in-class activities to engage dental students in each class, as presented in Table 1. Session 1 allowed students to watch 2-4 videos clips and/or to read weekly online materials before class. At the beginning of each class, student preparedness for class was tested by a 10-minute quiz. Session 2 started with a 20-minute mini-lecture, followed by a 90-minute discussion (session 3) that was evaluated by both tutors and peers. At the end of the course (session 4), the students were expected to take a final written test and to submit a reflective journal as a take-home exam. 


\begin{tabular}{|c|c|}
\hline & Contents \\
\hline Target & $\begin{array}{l}\text { Second-year pre-dental students admitted in } 2016 \\
\text { Five discussion groups were organized, and each group consisted of one facilitator and } 10 \text { students. }\end{array}$ \\
\hline Duration & A total of 15 weeks in the fall semester, 2017 \\
\hline Task & $\begin{array}{l}\text { Performing one module every week, from session } 1 \text { before class, through sessions } 2 \text { and } 3 \text { during class and to session } \\
4 \text { completing the final test and reflective journal (take-home exam) at the end of class five tutors were asked to take } \\
\text { turnsgiving a mini-lecture on each module, and they also (plus other two faculty members available in class time) participated } \\
\text { in group discussion facilitation. }\end{array}$ \\
\hline \multicolumn{2}{|r|}{ ( } \\
\hline \multicolumn{2}{|c|}{ Session 1: self-study before class } \\
\hline FCP student role & Study learning modules before tutorials; preview a discussion topic and research it; post individual comments online \\
\hline FCP tutor role & Upload or update online materials; make a quiz to diagnose level of understanding \\
\hline Assessment focus & Quiz: ability to understand basic knowledge and concepts \\
\hline \multicolumn{2}{|c|}{ Session 2: mini-lecture during class } \\
\hline FCP student role & Make a study note; pose a question; review comments \\
\hline FCP tutor role & Provide 20-min presentation; review what students studied online; offer theoretical background regarding the discussion topic \\
\hline Assessment focus & Discussion: ability to review the literature and use the gathered materials as cues for further study \\
\hline \multicolumn{2}{|c|}{ Session 3: topic-based discussion during class } \\
\hline FCP student role & Integrate information and apply it to the problem; trigger further enquiry \\
\hline FCP tutor role & Facilitate discussion; assess student preparedness and participation in discussion \\
\hline Assessment focus & Discussion: ability to interrelate concepts and present logical and critical thinking \\
\hline \multicolumn{2}{|c|}{ Session 4: final test \& reflective journal } \\
\hline FCP student role & Review all the topics covered in class; provide theoretical explanations supporting one's perspective \\
\hline FCP tutor role & Make a final test; list references for the reflective journal \\
\hline Assessment focus & $\begin{array}{l}\text { Final test: ability to provide a rationale that guides the questions being asked; reflective journal: ability to establish one's } \\
\text { own viewpoint concerning bio-diversity }\end{array}$ \\
\hline
\end{tabular}

FCP: Flipped Classroom Programs.

In this course, the total score comprised quizzes, discussion, reflective journal, final test, and attendance. The quiz was designed as formative test, and the final exam served as a summative test, and each counted as 30 points out of the total 100 . The in-class discussion skill was evaluated by both peer students (10 points) and tutors (10 points). Tutors also assessed the reflective journals (10 points) using rubrics, and 10 points were possible for attendance.

For the pre-dental student learning styles and MBTI types, a descriptive statistical analysis was conducted, and an independent samples $\mathrm{t}$-test was used to determine whether there were group differences in academic achievement. Also, multivariate regression analyses were adopted to examine the relationships between student self-rated measurements and academic achievement, which consisted of such domains as quizzes, discussion, reflective journal, attendance, and final test. As such, this study focused on whether student learning style and personality type affected the success of a flipped classroom of a pre-dental course. The STATA ver. 11.0 program (Stata Corp., College Station, USA) was used for statistical processing of analytical data.

\section{Results}

As suggested in Table 2, academic achievement, the average student total score was 61.01 out of 100 points. For learning style, which was one of the major independent variables, the assimilator (50\%), accommodator (16\%), converger (24\%), and diverger (10\%) 
types were the subjects of analysis, and the combined percentages of assimilators and convergers reached $74 \%$ of the overall ratio (Table 2).

The average between-group differences in terms of academic achievement, especially the total score, in- dicated no significant differences between groups in terms of gender and learning types (Table 3). However, the difference in performance between the diverger and non-diverger was statistically significant. In other words, the diverger group had a higher total score than

\begin{tabular}{clccc}
\hline \multicolumn{2}{l}{ Table 2. Descriptive Statistics for Measurements $(\mathrm{N}=50)$} & & & \\
\hline \multicolumn{1}{c}{ Category } & \multicolumn{1}{c}{ Mean \pm SD } & Min & Max \\
\hline Academic achievements & Total score & $61.01 \pm 12.98$ & 32.50 & 92.50 \\
& Quiz & $15.14 \pm 5.41$ & 4.80 & 26.60 \\
& Discuss peer assess & $7.76 \pm 2.80$ & 3.00 & 10.00 \\
& Discuss tutor assess & $9.33 \pm 0.71$ & 7.10 & 10.00 \\
& Reflect journal & $6.36 \pm 1.91$ & 2.00 & 10.00 \\
& Final test & $13.59 \pm 6.17$ & 3.20 & 29.30 \\
Individual factors & Attend & $8.84 \pm 0.92$ & 6.50 & 10.00 \\
& Cumulative GPA & $3.17 \pm 0.51$ & 2.15 & 4.18 \\
Learning styles & Gender & $0.50 \pm 0.50$ & 0.00 & 1.00 \\
& Diverger & $0.10 \pm 0.21$ & 0.00 & 1.00 \\
& Converger & $0.24 \pm 0.42$ & 0.00 & 1.00 \\
& Accommodator & $0.16 \pm 0.39$ & 0.00 & 1.00 \\
& Assimilator & $0.50 \pm 0.50$ & 0.00 & 1.00 \\
MBTI types & Extraversion & $9.20 \pm 6.25$ & 0.00 & 20.00 \\
& Introversion & $11.70 \pm 6.27$ & 1.00 & 20.00 \\
& Sensing & $15.26 \pm 5.74$ & 5.00 & 25.00 \\
& Intuition & $10.50 \pm 5.63$ & 1.00 & 20.00 \\
& Thinking & $11.86 \pm 6.51$ & 0.00 & 22.00 \\
& Feeling & $11.70 \pm 6.62$ & 2.00 & 24.00 \\
& Judging & $12.46 \pm 6.16$ & 0.00 & 21.00 \\
& Perceiving & $9.43 \pm 6.16$ & 1.00 & 22.00 \\
\hline
\end{tabular}

Cumulative GPA is the accumulation of previous semester GPA. Gender and learning styles are used as dummy variables. MBTI type is an index for score converted to continuous value.

SD: Standard deviation, GPA: Grade point average, MBTI: Myers-Briggs Type Indicator.

Table 3. Group Comparison in Academic Achievement by Gender and Learning Style

\begin{tabular}{llccc}
\hline \multirow{2}{*}{ Variable } & \multicolumn{3}{c}{ Total scores } \\
\cline { 2 - 5 } Gender & Male & No. of participants & Mean \pm SD & T-statistics \\
\multirow{2}{*}{ Diverger } & Female & 25 & $58.36 \pm 12.61$ & -1.45 \\
& If no & 25 & $63.65 \pm 13.05$ & \\
Converger & If yes & 45 & $61.21 \pm 12.48$ & $-2.14^{\text {al }}$ \\
& If no & 5 & $80.80 \pm 16.54$ & \\
Accomodator & If yes & 38 & $61.41 \pm 13.74$ & -0.63 \\
\multirow{2}{*}{ Assimilator } & If no & 12 & $64.43 \pm 11.00$ & \\
& If yes & 42 & $61.97 \pm 12.49$ & -0.13 \\
& If no & 8 & $62.67 \pm 16.60$ & \multirow{2}{*}{1.53} \\
\hline
\end{tabular}

Total score indicates the sum of scores for quizzes, discussion according to tutors and peers, reflective journal evaluation, and final written test. SD: Standard deviation.

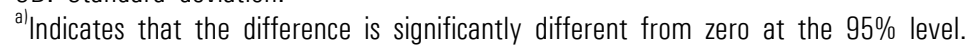




\begin{tabular}{|c|c|c|c|c|c|c|c|}
\hline \multirow[b]{2}{*}{ Variable } & \multicolumn{7}{|c|}{ Dependent variable: academic achievement } \\
\hline & Total score & Quiz & $\begin{array}{l}\text { Discuss peer } \\
\text { assess }\end{array}$ & $\begin{array}{c}\text { Discuss tutor } \\
\text { assess }\end{array}$ & Reflect journal & Final test & Attendance \\
\hline \multicolumn{8}{|l|}{ Individual factors } \\
\hline Cumulative GPA & $20.517^{b)}(3.428)$ & $8.312^{b)}(1.342)$ & $2.055(1.356)$ & 0.494 (0.284) & 0.910 (0.837) & $8.220^{b}(2.054)$ & $0.524(0.414)$ \\
\hline Gender & $1.745(3.552)$ & $1.856(1.390)$ & $2.454^{\mathrm{a})}(2.405)$ & $0.605^{-a)}(3.294)$ & $0.804(0.867)$ & $0.432(2.128)$ & $0.501(0.429)$ \\
\hline \multicolumn{8}{|l|}{ Learning styles } \\
\hline Converger & $-25.510^{b}(8.490)$ & $-10.544^{b l}(3.323)$ & 0.110 (3.358) & $0.880(0.703)$ & $-0.862(2.072)$ & $-14.434^{b}(5.086)$ & $-0.661(1.026)$ \\
\hline Accomodator & $-25.090^{3}(9.665)$ & $-5.778(3.783)$ & $-4.984(3.823)$ & $0.930(0.800)$ & -1.065 (2.359) & $-14.130^{a}(5.790)$ & $-0.063(1.168)$ \\
\hline Assimilator & $-29.104^{b)}(7.964)$ & $-10.200^{b}(3.117)$ & -2.404 (3.150) & $0.217(0.659)$ & $-1.224(1.944)$ & $-14.52 b^{b}(4.770)$ & $-0.966(0.963)$ \\
\hline \multicolumn{8}{|l|}{ MBTI types } \\
\hline MBTI extraversion-introversion & 0.050 (0.069) & $0.010(0.027)$ & 0.026 (0.027) & $-0.010(0.006)$ & $0.007(0.017)$ & $0.010(0.041)$ & 0.008 (0.008) \\
\hline MBTI sensing-intuition & $-0.129(0.075)$ & $-0.074^{a)}(0.029)$ & $0.033(0.030)$ & $-0.009(0.006)$ & $-0.007(0.018)$ & $-0.066(0.045)$ & $-0.006(0.009)$ \\
\hline MBTI thinking-feeling & -0.001 (0.069) & $0.006(0.027)$ & -0.002 (0.028) & $-0.087^{b /}(0.006)$ & $0.026(0.017)$ & $-0.016(0.041)$ & 0.002 (0.008) \\
\hline MBTI judging-perceiving & $0.008(0.065)$ & $0.005(0.025)$ & $-0.005(0.026)$ & $0.000(0.005)$ & $-0.018(0.016)$ & 0.018 (0.039) & $0.007(0.008)$ \\
\hline \multicolumn{8}{|l|}{ Model } \\
\hline F-statistic & $9.987^{b \mid}$ & $11.690^{b l}$ & 1.581 & $3.408^{\mathrm{al}}$ & 1.455 & $4.806^{9 /}$ & 1.261 \\
\hline Adjusted $\mathrm{R}^{2}$ & 0.764 & 0.794 & 0.173 & 0.464 & 0.141 & 0.578 & 0.086 \\
\hline Range of VIF & \multicolumn{7}{|c|}{$\operatorname{Min}=1.333, \max =8.658$} \\
\hline
\end{tabular}

Standard errors are in parentheses. Cumulative GPA is accumulation of previous semester GPA. Gender and learning styles are dummy variables, and male and diverger are used as a reference group. MBTI type is an index for score converted to continuous value. Bold type is considered statistically significant.

GPA: Grade point average, MBTI: Myers-Briggs Type Indicator; VIF: Variance inflation factor.

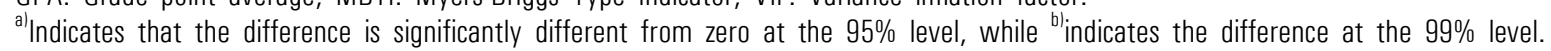

the non-diverger group.

In the multivariate regression analysis, the variables corresponding to the converger, accommodator, and assimilator were negatively significant for total, quiz, and final test scores. In other words, the divergers consistently showed higher academic achievement in a flipped classroom than the convergers, accommodators, and assimilators (Table 4). Cumulative grade point average (GPA), which denoted the accumulated grade point average of prior semesters, showed statistical significance for academic performance. The higher the cumulative GPA, the higher the student total, quiz, and final test scores in flipped learning.

Gender and MBTI thinking-feeling (TF) variables were statistically significant in discussion among academic achievement, which meant that female students and thinking types were more likely to perform better in discussion than were males and feeling types (Table 4).
The MBTI sensing-intuition variables showed a statistical significance in quizzes, confirming that the sensing type tended to have a higher quiz score than the intuition type.

\section{Discussion}

Recently, the flipped classroom model has been widely adopted in medical and dental education. However, in designing a flipped course, the instructors were unlikely to consider the student non-cognitive attributes for flipped learning success. These results confirmed the significant relationships between non-cognitive attributes and flipped learning outcomes in terms of learning style and personality type.

The learning style of the pre-dental students enrolled in a dental school showed a typical pattern, in which the 
assimilator and converger types were the most representative learning styles, supporting the consistent results. In a previous study analyzing the learning style of domestic medical students, the assimilator was also the most common, with the convergence being the second highest [15]. According to Kolb's learning theory [16], assimilators and convergers are more common in areas of natural sciences, with a greater interest in physical objects than people. On the other hand, accommodators and divergers are more popularly expressed among people in the humanities and social sciences, with greater interests in people than objects. In this regard, dental students typically conform to the pattern of natural sciences.

In this study, we demonstrated a strong relationship between the diverger group and academic performance. Divergers are able to consider alternatives and explore several possibilities to solve problems. Based on this characteristic, they often demonstrate better abilities in debate through rich imagination and insight $[15,16]$. In other words, the diverger group was more successful in a flipped learning classroom, which maximizes interaction between professor-student and student-student groups through learning activities, such as discussions and presentations that are unlikely to happen in vertical lecture classes.

Pre-dental student personality types were dominated by introverted, sensing, thinking, and judging types (ISTJ). In previous studies analyzing the learning styles of domestic medical students, the majority of the group was higher in introversion, sensing, thinking, and judging. As a whole, the high rates of ISTJ may reflect a systematic and structural tendency toward the outside world, rather than a flexible and adaptive one, in medical and dental students [15,17].

The MBTI TF was statistically significant regarding discussion, pointing out the notion that thinking types had higher discussion scores than feeling types. Even if MBTI TF did not affect the overall score of flipped learning, it could be assumed that the thinking type performed better in discussions that required momentary and intensive thinking skills. However, in the study highlighting the effect of personality type on problembased learning (PBL), only the judge-perceive variable was statistically significant, with the judging type being reported to perform better than the perceiving type [18]. The difference might be due to the notion that the characteristics of PBL that focuses primarily on solutions to given tasks could benefit the judging type, leading to higher performance.

Gender was found to be a relevant variable in regression analysis, with the average number of female students performing better than males in discussion. In this study, the female pre-dental students had higher discussion scores than males in a flipped-classroom. According to Reynold's study on gender differences in PBL, female students, who preferred studying individually, tended to show positive attitudes toward the cooperative system of PBL, in accord with the cooperative learning of in-class discussion [19].

Efforts to understand the learning styles and personalities constituting student non-cognitive characteristics are necessary. Because dental students tend to be one of the most academically competent groups in natural science, there is high possibility that the mutual distinction is more largely expressed in non-cognitive aspects relative to cognitive factors. Despite this, studies on learning strategies and styles have not been actively conducted in the field of medical and dental education [6,7]. It is therefore necessary to understand non-cognitive factors, such as learning style and personality type, for intellectual tasks and academic achievements and to foster a more efficient and effective teaching methodology. 
It is desirable to develop and apply a more tailored teaching method for dental school students in operating the flipped learning classroom. The results of this study confirmed that the majority of students in dental school have a learning style that matches the natural sciences, mainly in the form of the assimilator and converger. Developing more individualized teaching methods that consider the characteristics of dental students with relatively better strengths in drawing conclusions through the process of deliberation will be a more effective for educational pedagogy when operating a pre-dental flipped learning classroom, which is centered around interactive activities such as discussion.

This study was conducted on the students of such a single course in a dental school that it needs more follow-up research before its application in other flipped classrooms. Replicating this study in other medical and dental schools would provide higher reliability and a basis for determining generalization of the results. In addition, no analysis of dental proficiency was possible due to the use of GPA and course scores as the only measure of academic competence. More discussion is needed to develop additional assessment methods in examining flipped learning success.

This study suggests that dental instructors should carefully develop and apply a more learner-based facilitation and relevant assessment by considering student learning styles and personality types before implementing a flipped classroom approach. In other words, flipped classrooms can help to develop effective scaffolding strategies for active learning, especially by understanding student learning styles and personality types. Offering homogeneous instructions to individual students does not help to motivate active learning. Knowledge of personal preferences would encourage instructors to design a flipped course, which is more conducive for participation and better performance.

\section{ORCID:}

Minsun Kim: https://orcid.org/0000-0002-2968-2370;

Sangho Roh: https://orcid.org/0000-0001-8082-6459;

Jungjoon Ihm: https://orcid.org/0000-0002-3136-5956

Acknowledgements: None.

Funding: None.

Conflicts of interest: No potential conflict of interest relevant to this article was reported.

Author contributions: Design of the work, data collection: RS; data analysis, interpretation, and drafting the article: KM, IJ; and critical revision of the article, and final approval of the version to be published: IJ, RS.

\section{References}

1. Fulton KP. 10 Reasons to flip. Phi Delta Kappan. 2012; 94(2):20-24

2. Khanova J, McLaughlin JE, Rhoney DH, Roth MT, Harris S. Student perceptions of a flipped pharmacotherapy course. Am J Pharm Educ. 2015;79(9):140.

3. Heyborne WH, Perrett JJ. To flip or not to flip?: analysis of a flipped classroom pedagogy in a general biology course. J Coll Sci Teach. 2016;45(4):31-37.

4. Glyn Jones JC. Dental student selection: the prediction of success. J Dent. 1979;7(4):329-338.

5. Jones AC, Courts FJ, Sandow PL, Watson RE. MyersBriggs Type Indicator and dental school performance. J Dent Educ. 1997;61(12):928-933.

6. Smithers S, Catano VM, Cunningham DP. What predicts performance in Canadian dental schools? J Dent Educ. 2004;68(6):598-613.

7. Kim M, Kim S, Lee J, Ahn D, Lee Y. Characteristics of medical students' learning styles and their relationships to GPA. Korean J Med Educ. 2006;18(2):133-140.

8. Kim MJ, Park KP, Seo DG, Ihm JJ. The relationship 
between dental graduate students' MBTI types and academic achievement in problem-based learning. Korean J Med Educ. 2014;26(4):291-297.

9. Lawrence G. People types and tiger stripes: a practical guide to learning styles. 3rd ed. Gainesville, USA: Center for Applications of Psychological Type; 1993.

10. Pittenger DJ. The utility of the Myers-Briggs type indicator. Rev Educ Res. 1993;63(4):467-488.

11. Jung HK, Yoo YJ, Kim SO, Won DY, Kim MS. A study on the relationship between personality, learning attitude and academic achievement of nursing students. J Korean Acad Nurs Adm. 2007;13(4):516-525.

12. Lee EJ. Personality type on MBTI theory and academic achievement in design education. J Korean Soc Des Sci. $2011 ; 24(4): 13-22$.

13. Lee SJ. Relationships between MBTI's types and academic achievement of students in engineering college. Asian J Educ. 2013;14(2):189-212.

14. Kolb DA. Experimental learning: experience as a source of learning and development. Englewood Cliffs, USA Prentice-Hall; 1984.

15. Kim SH, Roh HR. The assessment of medical students' learning styles using the Kolb learning style inventory. Korean J Med Educ. 2007;19(3):197-205.

16. Kolb DA. The Kolb learning style inventory. Boston, USA: Hay Group; 2005.

17. Myers IB, McCaulley MH. Manual: a guide to the development and use of the Myers-Briggs Type Indicator. 2nd ed. Palo Alto, USA: Consulting Psychological Press; 1985.

18. Ihm JJ, An SY, Seo DG. Do dental students' personality types and group dynamics affect their performance in problem-based learning? J Dent Educ. 2017;81(6):744751.

19. Reynolds F. Initial experiences of interprofessional problem-based learning: a comparison of male and female students' views. J Interprof Care. 2003;17(1):35-44. 